\title{
Anterior segment optical coherence tomography findings of iris granulomas in Hansen's disease: a case report
}

\author{
Padmamalini Mahendradas ${ }^{1 *}$, Kavitha Avadhani ${ }^{1}$, Sarika Ramachandran ${ }^{1}$, Sahana Srinivas ${ }^{2}$, Madhavi Naik ${ }^{3}$ \\ and K Bhujang Shetty ${ }^{1}$
}

\begin{abstract}
Background: A 50-year-old male was diagnosed to have a right eye sclerouveitis and left eye granulomatous anterior uveitis due to Hansen's disease. We are reporting the anterior segment optical coherence tomography (ASOCT) findings of iris granuloma in this case.

Findings: Skin biopsy revealed plenty of acid fast bacilli with a bacteriological index of 5 suggestive of multibacillary polar lepromatous leprosy. ASOCT revealed well-demarcated smooth-surfaced nodular lesion with internal hyporeflectivity corresponding to the areas of granuloma which decreased in size following treatment with antileprosy drugs and systemic and topical steroids.

Conclusion: ASOCT is a non-invasive technique to assess the extent of involvement of anterior segment in Hansen's disease and is a useful tool in follow-up. This is also the first report on ASOCT findings of iris granuloma in Hansen's disease.
\end{abstract}

Keywords: Leprosy, Sclerouveitis, Anterior segment optical coherence tomography, ASOCT, Iris granuloma

\section{Findings}

Introduction

Leprosy (Hansen's disease or Hanseniasis) is one of the systemic diseases which can give rise to a plethora of features in the eye. The incidence of ocular involvement in leprosy has been variously quoted as $51 \%$ to $69 \%$ [1-3]. Iris nodules and lepra pearls are characteristics of the ocular manifestation of this disease and help in its diagnosis. In this study, we report the anterior segment optical coherence tomography (ASOCT) findings of iris granulomas in leprosy.

A 50-year-old gentleman presented to us complaining of watering in the right eye (OD) for 1 year, redness and diminution of vision for both distant and near for 2 months, bilateral headache and eye pain of 15-day duration. He was a known diabetic on medications for the past 1 year. He also gave history of undergoing treatment for dry, scaly

\footnotetext{
* Correspondence: m.padmamalini@gmail.com

'Department of Uveitis and Ocular Immunology, Narayana Nethralaya, 121/C, Rajajinagar, Bangalore, India

Full list of author information is available at the end of the article
}

skin lesions over the extremities in the past. On general physical examination, he had characteristic leonine facies with madarosis, depressed nasal bridge and broadening of the nose (Figure 1a). He also had thickened ear lobules (Figure 1b) and dry scaly patches of the skin over his extremities. His back showed bilaterally symmetrical patches of raised hypopigmented skin lesions.

On ocular examination, his best corrected visual acuity was 6/9, N10 in the right eye and 6/9, N8 in the left eye (OS). A nodular scleral mass lesion was noted in the right eye, adjacent to the limbus, around $3 \times 2 \mathrm{~mm}$ in size, extending into the anterior chamber (Figure 2a). Other findings in the same eye were the presence of circumciliary congestion, fine keratic precipitates, 2+ grade flare and cells with prominent iris vessels. In the left eye, a nodular mass lesion arising from the iris (Figure $2 \mathrm{~b}$ ) adjacent to the pupillary border, $1 \times 1 \mathrm{~mm}$ in size, was present. Iris pearls were also seen in the same eye along with circumciliary congestion, fine keratic precipitates, 2+ grade flare and cells and prominent iris vessels. Fundus examination of both eyes was 


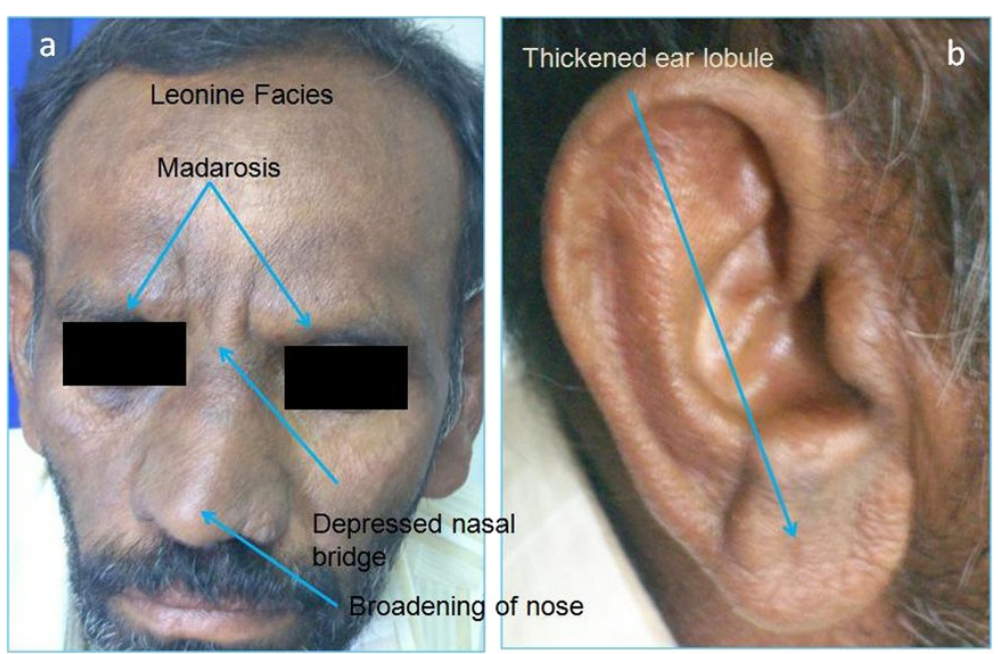

Figure 1 The face photograph of a 50-year-old man with leonine facies (a) and thickened ear lobule (b).

found normal. A clinical diagnosis of the right eye granulomatous sclerouveitis and the left eye granulomatous anterior uveitis secondary to polar lepromatous leprosy was made (Figure 2). ASOCT (Cornea/Anterior Segment OCT SS-1000, Tomey Corporation, Nagoya, Japan) was carried out in order to document the extent of lesion. Imaging of the right eye showed a welldemarcated smooth-surfaced nodular lesion, with internal hyporeflectivity and after shadowing, involving the limbal sclera extending on to the cornea and into the angle and anterior chamber (Figure 2c). The left eye imaging showed a well-demarcated nodular lesion arising from the anterior surface of the iris with hyporeflective internal echoes corresponding to the areas of iris granulomas (Figure 2d). Two other well-circumscribed smaller nodular lesions were present on the iris and were observed on imaging.

Routine blood and urine investigations, mantoux, chest X-ray and HIV I and II tests were all found to be negative. Slit skin smears taken from both ear lobules were found to be positive for lepra bacilli. Biopsy specimen taken from the raised papular lesion on the back showed thinning of the epidermis and dense infiltration of the dermis with foamy macrophages (Figure 3a). Specimen from the same lesion stained with Fite-Faraco stain and viewed under oil immersion $(\times 100$ magnification) showed plenty of acid fast bacilli teeming inside the foamy macrophages (Figure 3b). The bacteriological

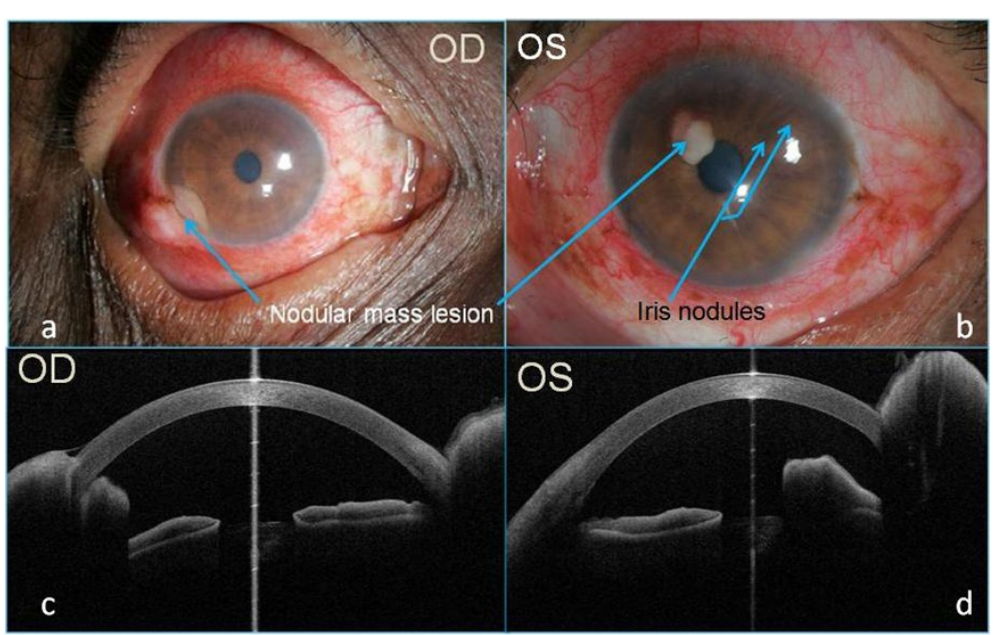

Figure 2 Granulomas in the eyes (a, b) and corresponding ASOCT findings (c, d). 


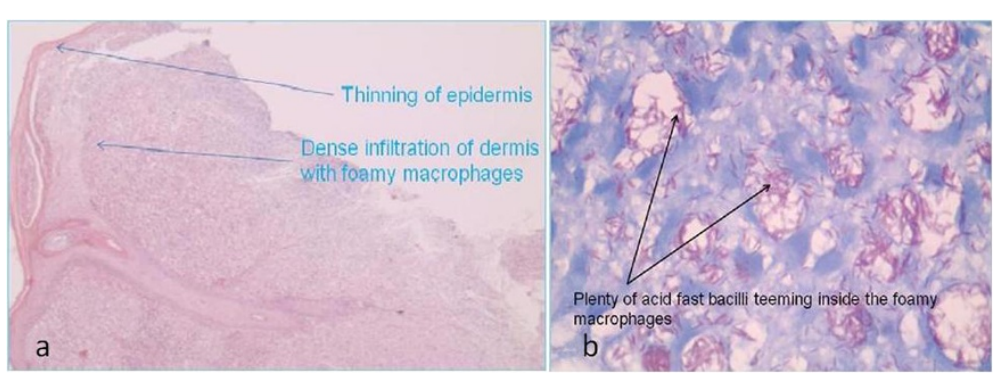

Figure 3 HPE shows foamy macrophages (a) and numerous acid fast bacilli (b).

index was found to be 5 (100 to 1,000 bacilli per highpower field). This bacteriological index put him in the category of multibacillary polar lepromatous leprosy.

He was put on the standard anti-leprosy systemic regime comprising of dapsone, rifampicin and clofazamine with systemic steroids (Figure 4). In addition, he was started on topical steroids and cycloplegics for the ocular manifestations. Following treatment, his vision improved in his right eye, the nodular lesion and the iris pearls started resolving and the keratic precipitates had also reduced. One month after starting the treatment, the patient was asymptomatic and the eyes were quiet with the lesions reduced in size (Figure 4). Resolving lesions in both eyes were documented on ASOCT (Figure 5,b,c,e,f). At the end of 2 months, lesions in both eyes healed completely. Written informed consent was obtained from the patient for publication.

\section{Discussion}

Ocular features commonly reported in leprosy are madarosis; lid abnormalities such as ectropion, entropion, trichiasis and lagophthalmos; dacryocystitis; chronic conjunctivitis; scleritis or episcleritis; and corneal involvement in the form of loss of corneal sensations, superficial keratitis, corneal opacities, interstitial keratitis, adherent leucoma, corneal ulcer or pannus and uveal involvement [2-5]. Three different types of uveal involvement have been described [5]: (a) typical acute granulomatous iridocyclitis with keratic precipitates, posterior synechiae and hypopyon with or without conjunctival leproma; (b) neuroparalytic uveitis in the form of dilator muscle atrophy; and (c) presence of iris pearls and lepra pearls with complicated cataract. Ocular hypotony in conjunction with hypotension has been reported in patients under therapy for multibacillary leprosy [6].

Ocular features noted in our patient were sclerouveal granuloma (leproma) with acute iridocyclitis in the right eye and iris leproma and iris pearls with acute iridocyclitis in the left eye. This case can be classified as type IV - immune-mediated granulomatous anterior uveitis due to leprosy [7]. Cornea was found to be the most commonly affected structure in the eye in a case

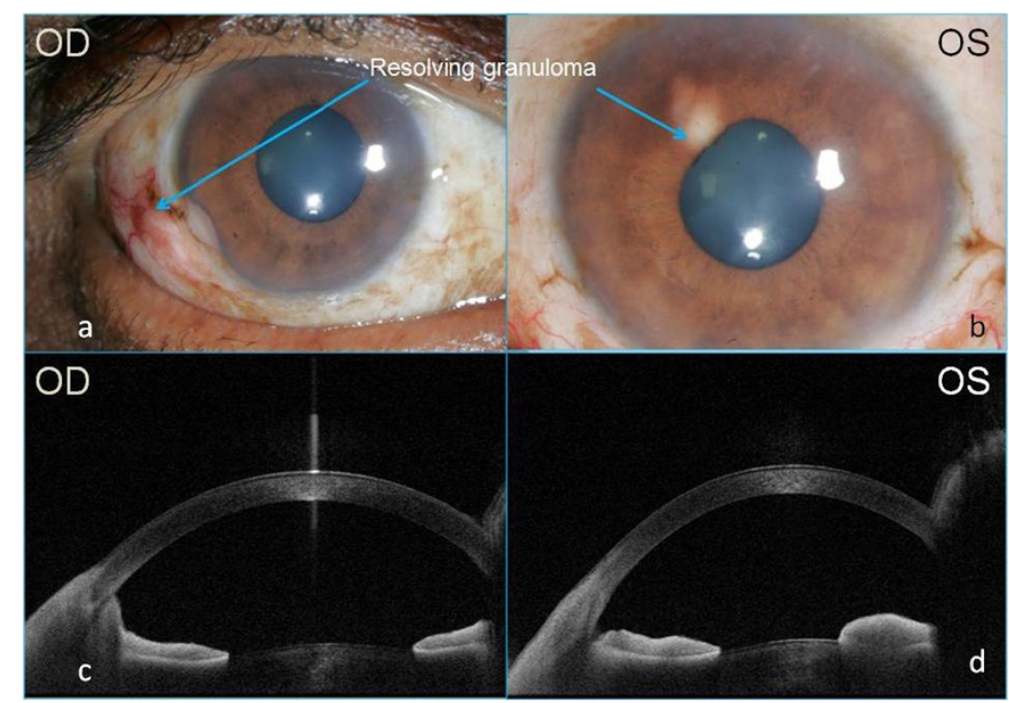

Figure 4 Resolving granulomas in the eyes $(a, b)$ and corresponding ASOCT changes (c, d). 

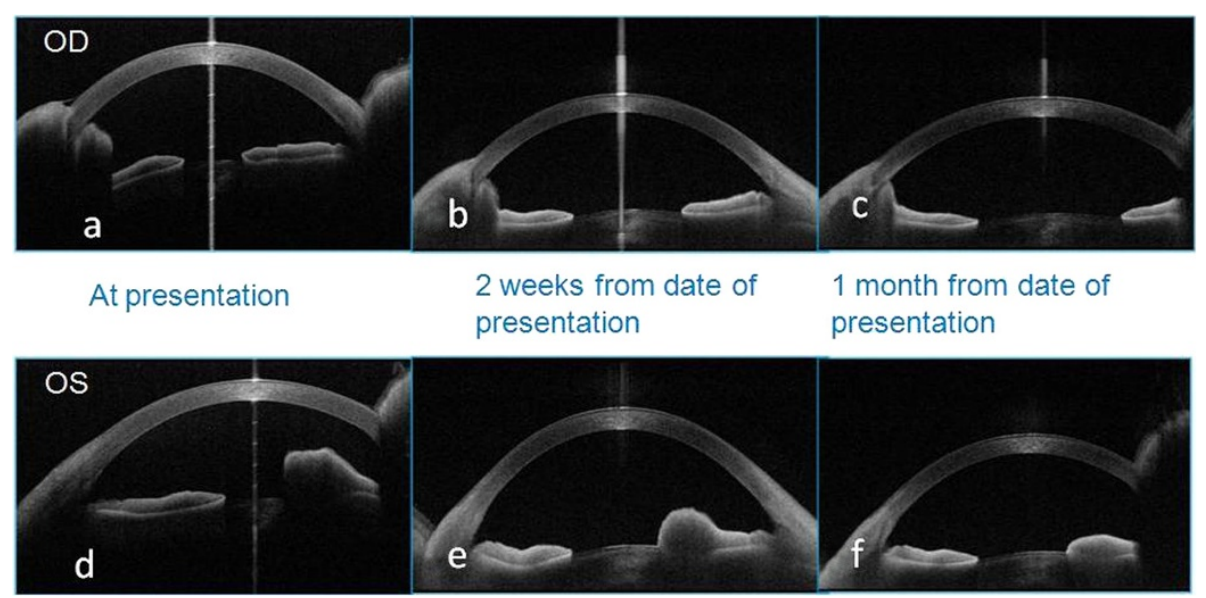

Figure 5 ASOCT features of iris granulomas at presentation $(a, d), 2$ weeks $(b, e)$ and 4 weeks $(c, f)$ post-treatment.

series studied by Sanjiv et al. [8], of which loss of corneal sensations was the most common finding which in our case was notably absent. Lagophthalmos is another common ocular finding which was absent in this case. Ocular leproma can be secondary to taking dapsone monotherapy irregularly and can signify dapsone resistance [9]. Incidentally, our patient gave history of having taken some medications for a few months for the dry scaly skin lesions which he discontinued by himself.

ASOCT imaging of granulomatous lesions has been described earlier in tuberculosis as poorly demarcated amorphous lesion [10] and as absorbent, hyporeflective areas [11]. The lesions in our case were well demarcated with internal hyporeflectivity and after shadowing. The extent of involvement was easily made out on ASOCT, but the limitation of optics disallows the interpretation of depth of lesion.

\section{Conclusions}

Granulomatous ocular leproma can be secondary to irregular anti-leprotic therapy or its discontinuation. Systemic steroids may be necessary along with antileprotic therapy for Immune-mediated granulomatous anterior uveitis seen in leprosy. ASOCT acts as a noninvasive technique to gauge the extent of involvement of anterior segment and is a useful tool for follow-up in patients of Hansen's disease with uveal involvement.

\section{Competing interests}

The authors declare that they have no competing interests.

\section{Authors' contributions}

PM contributed to the design, acquisition and interpretation of data, and drafted the manuscript. KA contributed to the acquisition of data and drafted the manuscript. SR contributed to the acquisition and interpretation of data, and drafted the manuscript. SS contributed to the acquisition, interpretation and management of the skin biopsy. MN contributed to the interpretation of the skin biopsy and drafted the manuscript. BS contributed to the collection of data, critical revision of the manuscript and funding. All authors read and approved the final manuscript.

\section{Author details}

'Department of Uveitis and Ocular Immunology, Narayana Nethralaya, 121/C, Rajajinagar, Bangalore, India. ${ }^{2}$ Department of Dermatology, St Theresa's Hospital, Rajkumar Road, Rajajinagar, Bangalore, India. ${ }^{3}$ Department of Pathology, Theresa's Hospital, Rajkumar Road, Rajajinagar, Bangalore, India.

Received: 5 October 2012 Accepted: 17 January 2013

Published: 11 February 2013

\section{References}

1. Chukka RK, Sheeladevi S, Pujari S (2011) Visual impairment in patients with leprosy in Adilabad district in the state of Andhra Pradesh, India. Indian J Lepr 83(3):131-137

2. Ebeigbe JA, Kio F (2011) Ocular leprosy in institutionalized Nigerian patients. Ghana Med J 45(2):50-53

3. Malik AN, Morris RW, Ffytche TJ (2011) The prevalence of ocular complications in leprosy patients seen in the United Kingdom over a period of 21 years. Eye (Lond) 25(6):740-745. doi:10.1038/eye.2011.43

4. Parikh R, Thomas S, Muliyil J, Parikh S, Thomas R (2009) Ocular manifestation in treated multibacillary Hansen's disease. Ophthalmology 116(11):2051.e1-2057.e1

5. Wani JS, Sabia R, Muzaffar S, Nasti AR (2005) Ocular manifestations of leprosy - a clinical study. JK Pract 12(1):14-17

6. Daniel E, Rao PS, Ffytche TJ, Courtright P (2010) Ocular hypotension and hypotony in multibacillary leprosy patients; at diagnosis, during and after completion of multidrug therapy. Indian J Lepr 82(4):181-188

7. Rathinam SR, Khairallah M, Hmidi K (2009) Anterior granulomatous uveitis in uveitis text \& imaging, 1st edn. Jaypee Brothers Medical Publishers(P) Ltd, India, pp 337-340

8. Sanjiv D, Rajiv D, Desai NC, Shoba L, Kumar K (1989) Ocular findings in the inmates of a leprosy rehabilitation centre. Indian J Ophthalmol 37:96-97

9. Reddy SC, Raju BD (2007) Ocular involvement in leprosy-a field study of 1004 patients. Int J Ophthalmol 7(3):590-596

10. Hashida N, Terubayashi A, Ohguro N (2011) Anterior segment optical coherence tomography findings of presumed intraocular tuberculosis. Cutan Ocul Toxicol 30(1):75-77

11. Banzhaf C, Jemec GB (2012) Imaging granulomatous lesions with optical coherence tomography. Case Rep Dermatol 4(1):14-18

doi:10.1186/1869-5760-3-36

Cite this article as: Mahendradas et al:: Anterior segment optical

coherence tomography findings of iris granulomas in Hansen's disease: a case report. Journal of Ophthalmic Inflammation and Infection 2013 3:36. 